arranged. After two weeks as an in-patient, all investigations including the VER were normal. The patient remained blind and required constant intensive nursing care.

A psychiatric referral was made and the following relevant background information was elicited: The patient had come to England at 27 years of age. She had lived with her parents and a paternal uncle until she was 32 years old. After a brief courtship she married a Mauritian man she had met at work. The marriage was consummated and this constituted her first sexual experience. Two weeks after the ceremony, the patient found her husband with another woman and left him, returning to her family home.

Her mental state examination revealed that she was depressed and obsessed with ruminations about black magic and evil spirits. On further interview of the patient and her 45-year-old uncle, it was clear that both of them were convinced that she had been possessed with an evil spirit, causing her blindness. At formulation it was decided that this woman was affected by a depressive illness accompanied by an hysterical conversion amaurosis. The content of the belief was in accordance with her cultural background and was not considered to be indicative of a paranoid psychosis. Following the first interview the patient was started on imipramine and valium. Two weeks later the situation was unchanged. Four weeks after admission to hospital hypnotherapy was first considered. At 2.05 p.m. on the 18th March 1981, two nurses led the patient into a side room of the general ward. As the patient had no knowledge of hypnosis a pragmatic introduction was given. She was told that she would be made to sleep. During this sleep the black magic making her blind would be destroyed. Using a progressive relaxation method, stage one was quickly passed and the patient rapidly passed into a somnambulistic state in response to firm suggestions of depth. As a test of the depth of trance a suggestion of paraesthesia in the right arm was given. The patient was told that she could feel the magic in her arm. Violent choreiform movements of the arm followed the suggestion and the patient became agitated. The suggestion was repeated and the subject told to concentrate on her eyes. In response to this command the patient started to gag loudly and breathed deeply with a loud stridor. She assumed an opisthotonic position on the bed. Synchronous with the suggestion that the magic causing her blindness had left her body, both eyes were lightly touched by the therapist. The patient collapsed from her rigid posture. Upon waking the patient sat up and proclaimed that she was no longer blind. Carefully replacing her slippers she walked unaided back into the ward. The time was 2.25 p.m.
This pragmatic application of hypnosis might well have been akin to what she would have received from a traditional healer in her native country, presumably with the same effect.

Upstate Medical Centre,

Peter A. Bick

Syracuse,

New York

\section{SENDING SCHIZOPHRENICS TO UNIVERSITY}

DEAR SIR,

It is becoming increasingly frequent to find students, both undergraduate and postgraduate, who have been diagnosed as being schizophrenic or schizoid and who are recommended to begin or continue their studies at university by their psychiatrist. These students are by no means always 'burnt out cases' (if indeed people in their twenties can ever be defined as such), and may be on regular medication, either orally or by injection.

Normally these people are seen by the psychiatrist in their home area, where the students have the advantage of living in a stable, known environment, under the care of their parents, and with low academic stresses. Universities, however, are places of great stress for psychotic people, where they have to live and care for themselves, and to contend with the often considerable academic stresses which prevail there. (This is even true of students living in halls of residence or in Oxford or Cambridge colleges).

When these students return or come to university they frequently break down again, usually quite soon: one such freshman broke down within three days here this term. May I make a plea for psychiatrists not to regard universities as places of peace and stability for psychotics (or anyone else for that matter)? They are in fact places where robust mental health is required, and they soon find out students with any weakness in that respect.

It is no kindness to send such people to university, and it often causes distress to them, their families at home and their co-students. I should add that in my experience over the last twenty years young psychotics are rarely 'cured' to the extent of being able to resume their university studies, whatever their past personalities may have been.

Health Centre,

$$
\text { T. C. DANN }
$$

University of Warwick,

Coventry CV4 $7 A L$

DeAR SiR,

As a psychiatrist who has treated psychotic students and returned them (successfully) to their studies (e.g. see 'Psychosis in Young Doctors', British Medical 